\title{
Do Cultural Intelligence and Language Learning Strategies Influence Students' English Language Proficiency?
}

\author{
Noor Rachmawaty \\ Universitas Negeri Makassar, Jln. Bonto Langkasa, Kampus Gunung Sari, Makassar, South Sulawesi, Indonesia \\ M. Basri Wello \\ Universitas Negeri Makassar, Jln. Bonto Langkasa, Kampus Gunung Sari, Makassar, South Sulawesi, Indonesia \\ Mansur Akil \\ Universitas Negeri Makassar, Jln. Bonto Langkasa, Kampus Gunung Sari, Makassar, South Sulawesi, Indonesia \\ Syarifuddin Dollah \\ Universitas Negeri Makassar, Jln. Bonto Langkasa, Kampus Gunung Sari, Makassar, South Sulawesi, Indonesia
}

\begin{abstract}
Cultural Intelligence (CQ) is believed as an additional type to the existing forms of intelligence (IQ, EQ). It also explains why some individuals are more effective than others in culturally diverse situations. Studies have documented how successful language learners seem to use wider variety of language learning strategies than unsuccessful learners. Having these two important aspects in relation to the successfulness of acquiring foreign language thus this study is intended to explore the relationship of Cultural Intelligence, Language Learning Strategy and English Language proficiency. The study involved 87 second-year students of English Department, Mulawarman University. Data were gathered using The Cultural Intelligence Scale (CQS), The Strategy Inventory for Language Learning (SILL) and TOEFL. Descriptive and inferential statistics using SPSS 20 were used in the process of data analysis. The result reveals that CQ level of the students is medium $(M=51.984)$ with metacognitive and motivational as dominant factors for both male and female students. The data shows that there is a significant relationship between CQ and $L L S(F=13.082, p=$ 0.001). This result confirms the previous studies that culture influences the frequency and type of LLS use. As for strategy categories, metacognitive is the most frequently used strategy $(M=3.704)$ and affective is the least frequently used $(M=3.080)$. The students' proficiency level is ranging from elementary $(25.29 \%)$ to advanced $(\mathbf{8 . 0 5 \%})$. The dominant level is low intermediate. The data recorded that there is no correlation among cultural intelligence, language learning strategies and English language proficiency $(F=1.208, p=0.304)$.
\end{abstract}

Index Terms - cultural intelligence, language learning strategies, English language proficiency

\section{INTRODUCTION}

A great deal of technological innovations in different fields such as communications, transportation, and various information tools have contributed to create the greatest blend of cultures in the world (Lustig and Koester, 2010). As a result of the rapid growth of globalization, technology development and population migration (Chen and Starosta, 2008), English Language Teaching in the 1980s recognized the need for communication with people from other cultures. It then resulted in the intercultural perspective towards language teaching (Derin et al., 2009). Based on this perspective, the competence is not being a native-like; rather, it is an intercultural one (Corbett, 2003) through which students "decenter from their own linguistic and cultural situation to consider that of others" (Scarino, 2009) and improved positive attitudes and reduced sense of ethnocentrism towards different culture (Schultz, 2007). In this perspective, culture is seen as an important part of foreign language learning and instruction. Thanasoulas (2001) noted how language and culture are interrelated as culture help people to identify not only speaker and listener, topic of the conversation but also help people to better understand how to identify messages, meaning behind the message and the contexts However, the manner in which culture is often presented often does not meet the expectations and needs of an increasingly communicated world.

With regards to the importance of culture, researchers' extensive review of intercultural theory and intelligence approach led to the early conceptualization of cultural intelligence (CQ). It is an intelligence which has the same basic root other intelligences but the focus is particularly on having the skill needed to be effective in the globalized, interconnected world (Livermore, 2011). Further he emphasizes that CQ adds to the existing forms of intelligence (IQ, $\mathrm{CQ}$ ) and explains why some individuals are more effective than others in culturally diverse situations. The reason lies basically on the fact that norms for interaction are different from one culture to another. 
A large and extensive number of researches have been conducted on the topic of language learning strategy use (e.q. Larsen-Freeman \& Long, 1991; O’Mailey \& Chamot, 1990; Oxford, 1990) which resulted in an agreement that language learning strategy is one of the most important factors in second language acquisition process. in similar vein, many studies in second language learning (e.q. Oxford, 1990; Green \& Oxford, 1995; Wharton, 2000, Griffiths \& Parr, 2001) have documented how successful language learners seem to use wider variety of language learning strategies than unsuccessful learners. In addition selecting appropriate language learning strategies could enhance the learners' performance of second language learning (Oxford, 1990; Bruen, 2001).

Regarding the role of language learning strategy in the successfulness of a second or foreign language learner, studies provide several factors which may affect the choice and use of the strategies. Gardner and MacIntyre (1993) point out that the relationship between language learning strategies and other individual factors such as intelligence, aptitude, attitudes, motivation and anxiety is complex. Other potential learner variables which may affect the choice of language learning strategies are personality, learning style, beliefs and personal circumstances. Three factors which commonly regarded to have an impact on learners are the variables of nationality, sex and age.

Knowing how powerful language learning strategy for a learner to take part in the learning his or her own learning process and the fact that individual within cultures differ and bring different personality traits should be uphold in order to promote culturally responsive education system which will speed up the successfulness of learners. In addition, there is still more to delve on the existence of Cultural Intelligence (CQ) in the field of foreign language education. Therefore, a study which investigated the extent of CQ as the mediator of the relationships between language learning strategies and language proficiency is necessary to be carried out as it will shed a different insight to the existence knowledge about CQ.

It is also derived from the previous studies that most studies which explored the relationship between Cultural Intelligence (CQ) and language skills were carried out in middle-east, little or even no empirical study has been conducted in Indonesia especially East Kalimantan. This study involved second-year students of English Department, Mulawarman University. They are chosen as they fit into the criteria set for this study.

This study is aimed at answering the following questions:

1. How are the Cultural Intelligence Level, Language Learning Strategy Use and English Proficiency Level of the Students?

2. Is there any difference in Cultural Intelligence Level, Language Learning Strategy Use and English Proficiency Level of the Students by gender?

3. Is there a relationship between Cultural Intelligence, Language Learning Strategies and English proficiency among the English Department students?

\section{Cultural Intelligence}

Globalization, multiculturalism and international status of the English language have urged English as second or foreign language learners to develop their Cultural Intelligence (CQ) as it acknowledges the practical realities of globalization (Earley and Ang, 2003) and complements Intelligence Quotient (IQ) by focusing on specific capabilities that are important for high quality personal relationships and effectiveness in culturally diverse settings (Ang, Van Dyne and Koh, 2006). In the same vein Ramis and Krastina (2010) point out that CQ goes beyond the concept that intelligence is based solely on cognitive and/or practical skills. It is one step ahead as it consists of academic intelligence (acquired in academic context), practical intelligence (acquired in daily context) and communicative intelligence.

Cultural Intelligence was first introduced by Earley and Ang (2003), their work draws on Stemberg and Detterman's (1986) cited in Ng, Dyne and Ang (2012) which look at an integration of multiple loci of intelligences which proposed a set of capabilities covering mental, motivational, and behavioral components that concentrating mainly on resolving cross-cultural problems. CQ incorporates four qualitatively different constructs which include metacognitive CQ, cognitive CQ, motivational CQ and behavioral CQ.

Language Learning Strategies

The definition of learning strategies was firstly proposed by Rubin (1975). She defined learning strategies as techniques used by learners to acquire knowledge. Further she came up with the categorization of learning strategies, they are direct strategies and indirect strategies. The direct learning strategies involve clarification/verification, monitoring, memorization, guessing/inductive inferencing, deductive reasoning and practice while the indirect learning strategies consist of creating opportunities for practice and production tricks.

Oxford (1990) conducted thorough literature studies on language learning strategies which resulted in recommending the categorization into: memory strategies (strategies to remember language), cognitive strategies (strategies to acquire knowledge about language), compensation strategies (strategies to deal with limited knowledge), metacognitive strategies (strategies to cope with learning process), affective strategies (strategies related to students' feelings), social strategies (strategies that adopt learning by interaction with others).

Definition and the measurement of English Language Proficiency

Language proficiency has been one of the popular topics in second or foreign language research, however defining and determining proficiency in language learning for speakers of other languages is no easy endeavor. According to the traditional view proficiency is mainly related to grammar and lexis (Harley, Allen, Cummins and Swain (1990). Along 
with the development of research in second and foreign language, proficiency deals with the degree of skill with which a language can be used (Richards, Platt and Platt, 1985). Yet, the word 'skill' opens a debate on its content in language, also the importance of fluency over accuracy and vice versa (Brumfit 1984), or on whether skills such as reading, writing, listening and speaking should be separated from elements of knowledge such as grammar, vocabulary, pronunciation and cultural awareness (Lado, 1961).

In a more practical definition, Lange (1990) defines foreign language proficiency as the ability to use the language modalities (listening, reading, writing and speaking), and to assume the cultural framework of the language being studied for the purpose of communicating ideas and information. Similarly, the Ohio Department of Education on their website (2017) provides definition of language proficiency as the ability of individual to use culturally appropriate language to communicate spontaneously in non-rehearsed context. Further they add that proficiency also refers to the degree of skill with which a person can use a language to understand, speak, read and write in real life situations.

There are different types of measurement used to measure the proficiency of a language learner, two of which are extensively used tests, they are Test of English as a Foreign Language (TOEFL) and the International English Language Testing System (IELTS). Apart from being extensively used in almost 130 countries in the world, there are critics related to its validity as well as reliability. It is the construct validity of TOEFL, the multiple choice format is regarded not testing the 'real' language. Regarding the questionable case of its validity and reliability, many colleges and universities in the world still use either one of the test as one of the requirements to enter the university.

In this current study, the researcher chooses TOEFL as a measurement as this type of test is the most familiar test for the students under study. It is also representative in measuring the proficiency of the students as it covers three main sections with different aims of testing.

\section{METHOD}

This study was correlational as it aimed at revealing the relationship of Cultural Intelligence, Language learning strategies and English Language Proficiency. Gall, Gall, \& Borg (2007) argue that the correlational research designs are useful in predicting the relationship between variables.

The present study involved the fifth semester students of English Department, Faculty of Teacher Training and Education, Mulawarman University East Kalimantan and they were approximately 120 students. However, only 87 students were willing to join the study. The reasons choosing this particular group of students are related to the number of skill subjects (Listening, Speaking, Reading and Writing) that they had taken in the previous years assumed to equip them to have certain language proficiency in English, the length of time they have spent in academic life in campus has helped them to exercise their academic and socio-cultural skills in real life situations and lastly the specific subject about Cross Cultural Understanding that they had might give them background knowledge when they are asked about culture and its related factors.

\section{RESULTS AND DISCUSSION}

This section is arranged in accordance with the aforementioned research questions. The findings from Cultural Intelligence questionnaire, SILL and proficiency test were statistically analyzed and discussed in relation to findings from previous studies.

Research Question 1: How are the Cultural Intelligence Level, Language Learning Strategy Use and English Proficiency Level of the Students?

Responding to the first research question, Table 1 describes the level of students' Cultural Intelligence with the Medium level as the most dominant level (74.713\%) then followed by High (16.092\%) and finally Low level (9.195\%).

TABLE 1

STUDENTS' CULTURAL INTELLIGENCE LEVEL

\begin{tabular}{llll}
\hline Cultural Intelligence & & \multirow{2}{*}{ Frequency } & Percentage (\%) \\
\hline Interval & Category & 0 & 0 \\
$80<\mathrm{X} \leq 100$ & Very High & 14 & 16.092 \\
$60<\mathrm{X} \leq 80$ & High & 65 & 74.713 \\
$40<\mathrm{X} \leq 60$ & Medium & 8 & 9.195 \\
$20<\mathrm{X} \leq 40$ & Low & 0 & 0 \\
$0<\mathrm{X} \leq 20$ & Very Low & 87 & 100 \\
Total & & 71.429 & \\
Maximum Score & & 28.571 & \\
Minimum Score & & 51.984 & \\
Average & & 8.439 & \\
Standard Deviation & & 71.209 & \\
Variance & & & \\
\hline
\end{tabular}

The overall use of language learning strategies by the students is shown in Table 2. This table presents the frequency of strategy use among all the students. The percentage of strategy use ranged from a very high $4.598 \%$ to a low of 
$2.299 \%$. The table also shows that most students use language learning strategy in medium level as can be seen from the average score that is 59.106 .

TABLE 2

STUDENTS’ LANGUAGE LEARNING STRATEGY USE

\begin{tabular}{llll}
\hline SILL & & \multirow{2}{*}{ Frequency } & Percentage $(\%)$ \\
\hline Interval & Category & & \\
\hline $80<\mathrm{X} \leq 100$ & Very High & 4 & 4.598 \\
$60<\mathrm{X} \leq 80$ & High & 35 & 40.230 \\
$40<\mathrm{X} \leq 60$ & Medium & 46 & 52.874 \\
$20<\mathrm{X} \leq 40$ & Low & 2 & 2.299 \\
$0<\mathrm{X} \leq 20$ & Very Low & 0 & 0 \\
Total & & 87 & 100 \\
Maximum Score & & 90.000 & \\
Minimum Score & & 23.889 & \\
Average & & 59.106 & \\
Standard Deviation & & 10.418 & \\
Variance & & 108.531 & \\
\hline
\end{tabular}

A TOEFL prediction test was conducted in order to know students' proficiency level. Table 3 describes the students' proficiency level ranging from elementary with the total percentage $25.287 \%$ to advance with the total percentage $8.046 \%$. The most dominant level is low intermediate with almost half of the total sample is categorized in this category.

TABLE 3

STUDENTS’ PROFICIENCY LEVEL

\begin{tabular}{llll}
\hline Proficiency Level & & Frequency & Percentage (\%) \\
\hline Interval & Category & 7 & 8.046 \\
\hline $525-$ Above & Advanced & 14 & 16.092 \\
$480-520$ & High Intermediate & 44 & 50.575 \\
$420-480$ & Low Intermediate & 22 & 25.287 \\
$310-420$ & Elementary & 87 & 100 \\
Total & & 590 & \\
Maximum Score & & 316 & \\
Minimum Score & & 448.01 & \\
Average & & 49.05 & \\
Standard Deviation & & 2405.94 & \\
Variance &
\end{tabular}

Research Question 2: Is there any difference in Cultural Intelligence Level, Language Learning Strategy Use and English Proficiency Level of the Students by gender?

The next description on Table 4 displays students' Cultural Intelligence based on gender and the four factors of Cultural Intelligence.

TABLE 4

STUDENTS' CULTURAL INTELLIGENCE BASED ON GENDER

\begin{tabular}{llll}
\hline \multirow{2}{*}{ Cultural Intelligence Factors } & $\begin{array}{l}\text { Gender } \\
\text { Male Students }\end{array}$ & Female Students & Total Average \\
\hline Metacognitive & 3.444 & 3.537 & 3.518 \\
Cognitive & 3.167 & 2.925 & 2.975 \\
Motivational & 3.200 & 3.412 & 3.368 \\
Behavioral & 2.900 & 3.267 & 3.191 \\
\hline
\end{tabular}

Based on the Table 4, the most dominant factor which influences students' level of cultural intelligence is the Metacognitive factor $(M=3.518)$ then followed by Motivational factor $(M=3.368)$ and Behavioral factor $(M=3.191)$ while the least is Cognitive factor $(\mathrm{M}=2.975)$. Both male and female students' cultural intelligence level is influenced by metacognitive factor that is individual's cultural consciousness and awareness during interactions with people who have different cultural backgrounds (Van Dyne, L., Ang, S., and Koh, C.K.S., 2009). However, the least dominant factor that influences the female and male groups is different. The Female students' Cultural Intelligence level is influenced less by the cognitive factor $(M=2.925)$ while behavioral factor becomes the least dominant influence for the male students' Cultural Intelligence level.

The description of the most dominant strategy used by students referring to their gender can be seen in Table 5 . 
TABLE 5

DESCRIPTION OF OVERALL USE OF LANGUAGE LEARNING STRATEGIES

\begin{tabular}{llll}
\hline SILL & Gender & & \\
& Male Students & Female Students & Total Average \\
\hline Memory strategy & 3.118 & 3.197 & 3.181 \\
Cognitive strategy & 3.214 & 3.439 & 3.392 \\
Compensation strategy & 3.322 & 3.371 & 3.361 \\
Metacognitive strategy & 3.525 & 3.750 & 3.704 \\
Affective strategy & 2.741 & 3.169 & 3.080 \\
Social strategy & 3.222 & 3.290 & 3.276 \\
Total & 3.209 & 3.405 & 3.364 \\
\hline
\end{tabular}

As for strategy categories, metacognitive strategy is the most frequently used strategy $(\mathrm{M}=3.704)$ and affective strategy is the least frequently used $(\mathrm{M}=3.080)$, while between the two descending order are cognitive strategy $(M=3.392)$, compensation strategy $(M=3.361)$, social strategy $(M=3.276)$ and memory strategy $(M=3.181)$. With regards to gender, both female and male students use metacognitive strategy as the most frequently used strategy and affective strategy as the least frequently used.

Research Question 3: Is there a relationship between Cultural Intelligence, Language Learning Strategies and English proficiency among the English Department students?

In relation to the linkage between cultural intelligence, language learning strategies and English language proficiency, the computation from one way analysis of variant (ANOVA) shows a meaningful relationship between cultural intelligence and language learning strategies $(F=13.082, p=0.001)$.

TABLE 6

THE CoRrelation BETWEen CULTURAL INTELLIGENCE AND LANGUAGE LEARNING STRATEGIES ANOVA $^{\mathrm{a}}$

\begin{tabular}{|ll|l|l|l|l|l|}
\hline Model & $\begin{array}{l}\text { Sum of } \\
\text { Squares }\end{array}$ & df & Mean Square & F & Sig. \\
\hline \multirow{2}{*}{1} & Regression & 1259.377 & 1 & 1259.377 & 13.082 & $.001^{\mathrm{b}}$ \\
& Residual & 8182.709 & 85 & 96.267 & & \\
& Total & 9442.086 & 86 & & & \\
\hline
\end{tabular}

a. Dependent Variable: SILL

b. Predictors: (Constant), C.I

ANOVA was also used to find out the correlation among the three variables, they are Cultural Intelligence, Language Learning Strategies, and English Language Proficiency. The result shows that there is no correlation among the variables $(F=1.208, p=0.304)$.

TABLE 7

THE CORRELATION AMONG CQ, SILL AND ENGLISH PROFICIENCY

\begin{tabular}{|c|c|c|c|c|c|}
\hline Model & $\begin{array}{l}\text { Sum of } \\
\text { Squares }\end{array}$ & $\mathrm{df}$ & Mean Square & $\mathrm{F}$ & Sig. \\
\hline $\begin{array}{l}\text { Regression } \\
\text { Residual } \\
\text { Total }\end{array}$ & $\begin{array}{l}5853.018 \\
203463.970 \\
209316.989\end{array}$ & $\begin{array}{l}2 \\
84 \\
86\end{array}$ & $\begin{array}{l}2926.509 \\
2422.190\end{array}$ & 1.208 & $.304^{\mathrm{b}}$ \\
\hline
\end{tabular}

a. Dependent Variable: TOEFL

b. Predictors: (Constant), SILL, C.I

Cultural Intelligence and the frequency of Language Learning Strategies use adopted by the students

With regards to the correlation between Cultural Intelligence and the frequency of language learning strategies use, Table 8 describes that the cultural intelligence factors, particularly metacognitive influences both frequent and less frequent use of language learning strategies. The next factor that is assumed to give influence on language learning strategies use is motivational then followed by behavioral and the last is cognitive.

TABLE 8

CULTURAL INTELLIGENCE FACTORS AND THE FREQUENCY OF LANGUAGE LEARNING STRATEGIES USE

\begin{tabular}{lll}
\hline \multirow{2}{*}{ Cultural Intelligence Factors } & SILL Frequency \\
\cline { 2 - 3 } & High & Low \\
\hline Metacognitive & 3.558 & 3.271 \\
Cognitive & 3.009 & 2.764 \\
Motivational & 3.448 & 2.867 \\
Behavioral & 3.248 & 2.833 \\
Total & 3.288 & 2.908 \\
\hline
\end{tabular}

Cultural Intelligence and the students' English language proficiency

This study reveals that the link between factors in Cultural Intelligence (CQ) and the level of language proficiency was not significant. However, there are several results which could be used to inform the students' current condition 
related to cultural intelligence and proficiency level. The data indicates that high proficiency students reported have higher mean score in two factors of CQ compares to the low proficiency students. To be more precise, the proficient students seemed to be influenced by metacognitive and cognitive factors while the less proficient students were directed by motivational and behavioral factors.

TABLE 9

CULTURAL INTELLIGENCE FACTORS AND PROFICIENCY LEVEL

\begin{tabular}{lll}
\hline \multirow{2}{*}{ Cultural Intelligence Factors } & Proficiency Level \\
\cline { 2 - 3 } & High & Low \\
\hline Metacognitive & 3.738 & 3.448 \\
Cognitive & 3.183 & 2.909 \\
Motivational & 3.333 & 3.379 \\
Behavioral & 3.124 & 3.212 \\
Total & 3.317 & 3.210 \\
\hline
\end{tabular}

Language learning strategies and English language proficiency

The statistics computation shows that there was no correlation between language learning strategies and English language proficiency. Nevertheless, several data might be used to reveal additional information regarding the result of the study. The data shows that high proficiency students reported to have relatively higher mean score in all of the six strategy categories than the low proficiency students The proficient students used all types of strategies more frequently than the less proficient students except on the affective strategy $(M=2.976)$. The most preferred strategy types for the high proficiency students were Metacognitive strategy $(\mathrm{M}=3.841)$ and Compensation strategy $(\mathrm{M}=3.514)$ respectively, while for the less proficient students Metacognitive strategy $(M=3.660)$ and Cognitive strategy $(M=3.380)$ were the most favorable strategy types. It is interesting to note that both high and low proficiency students prefer to use metacognitive strategy than other language learning strategies.

TABLE 10

LANGUAGE LEARNING STRATEGIES AND ENGLISH PROFICIENCY LEVEL

\begin{tabular}{lll}
\multicolumn{3}{c}{ LANGUAGE LEARNING STRATEGIES AND ENGLISH PROFICIENCY LEVEL } \\
\hline \multirow{2}{*}{ SILL } & Proficiency Level & \\
\cline { 2 - 3 } & High & Low \\
\hline Memory strategy & 3.196 & 3.176 \\
Cognitive strategy & 3.432 & 3.380 \\
Compensation strategy & 3.514 & 3.312 \\
Metacognitive strategy & 3.841 & 3.660 \\
Affective strategy & 2.976 & 3.114 \\
Social strategy & 3.413 & 3.232 \\
Total & 3.419 & 3.346 \\
\hline
\end{tabular}

Culture is assumed to give influence on the language learning strategies used by a second or foreign language learner as culture is embedded in the context where the learner live. In line with this idea, Oxford (1990) points out that the frequency and type of learning strategy use influenced with factors such as degree of awareness of learning strategies, stage of learning, task requirements, age, gender, cultural and mother language background, purpose of learning, personality traits, and motivation. The findings of the current support Oxford's (1990) argument with regards to the argument that culture influences the frequency and type of language learning use. This study also in line with the previous research related to the correlation between culture and language learning strategies Harsch and Riley (1998) cited in Macaro (2001) conducted a study which compares adult ESL and EFL learners in two different countries, Hawaii (USA) and Japan. The study looked at the teaching approaches that were used as contexts to discuss the differences between the ways that the learners in these two countries use strategies. It was revealed that ESL students reported greater use of LLS than EFL students. Being in an English-speaking environment made the ESL students more aware of strategy use. The finding of Harsch and Riley's study (1999) lead another studies to find out about the role of culture in relation to language learning strategies. Wharton (2000) conducted a study involving bilingual students with Chinese ethnicity background at a Singaporean university. The students studied a foreign language (French or Japanese). It was found that the students favored social strategies the most but reluctant to use affective.

Based on the result of the study, it can be assumed that the influence of culture on the frequency and types of language learning strategy use can be seen through the existence of certain cultural intelligence level. In this study, the average level of cultural intelligence is categorized as medium $(\mathrm{M}=51.984)$ with metacognitive and motivational factors, respectively as the dominant factors that constitute the level of cultural intelligence. Metacognitive factor is considered as the critical component for cultural intelligence because of several reasons, the first, it promotes active thinking, about people and situations when differences are found regarding cultural backgrounds. Second, it triggers critical thinking about habits, assumptions, and culturally bound thinking. The last, it lets a person to evaluate and revise their mental maps which will increase the level of understanding (O’Neil and Abedi, 1996; Pintrich and DeGroot, 1990 cited in Van Dyne, Ang and Koh, 2009). The metacognitive factor of CQ promotes an individual's cultural consciousness and awareness of different cultural backgrounds when facing the process of learning a foreign language. Having this in mind, help the students to choose which strategy to adopt when learning English and how frequent to use the strategies. 
Based on the findings, it is noted that the motivational factor of cultural intelligence also contributes to the current level of students' cultural intelligence under this study. Van Dyne, Ang and Koh (2009) define that this factor is related to the capability of an individual in directing attention and energy toward cultural differences. The motivational factor strengthens the individual's self-efficacy and intrinsic motivation in using certain language learning strategies to promote the process of English foreign language learning.

Given the arguments of how cultural intelligence plays an important role in students' preference of language learning strategies and the frequency of applying them, it is necessary to note that English teachers should promote a culturally responsive teaching atmosphere in their classroom. This type of classroom will help students' level of cultural intelligence improved as it provides more opportunities on cross-cultural interactions. High level of cultural intelligence is assumed to encourage students to better understand their own culture and the foreign culture that they are learning. With this understanding, they could direct themselves to be good language learners who know the most suitable strategies to use that fit to their personality and cultural backgrounds.

The data revealed that there was no correlation between the three variables though Cultural Intelligence and Language Learning Strategies were significantly correlated. The results of the current study seem contradict to the result from the previous researchers. Previous study which looked at similar area that is the relationship between cultural intelligence and English language proficiency was conducted by Khodadady and Ghahari (2012). The study used Cultural Intelligence in Persian version and a disclosed test of English as a Foreign Language (TOEFL) as the instruments for gathering data. There were forty five undergraduate university students majoring various fields of knowledge in three Iranian Universities. The result showed negative but significant correlation between Cultural Intelligence and English Language Proficiency. In addition, when the EFL learners were divided into High, Middle and Low level of proficiency, there was a significant but negative correlation particularly with Cognitive and Motivational factors for the middle level proficiency group. The differences found between current study and Khodadady and Ghahari's (2012) study were possibly associated with major of the study of the participants, individual differences and context where the study was carried out.

The current study seemed revealing similar results to study conducted by Marcum (2017) who investigated the predictive relationship between Cultural Intelligence and Language Proficiency in distance English-language program. The findings showed that cultural proficiency did not predict students' language proficiency at the beginning of the course, during and at the end of the course.

In relation to the results of the current study, correlation did not exist between the variables. Thus, this study disconfirms the proposed linkage model of cultural intelligence, language learning strategies and English language proficiency. In addition, it can be assumed that language learning strategies did not have any role either as mediator or moderator in the relationship between cultural intelligence and English language proficiency. In attempt to understand more about the finding which showed no correlation among the variables, the level of students' language proficiency were divided into high and low group. The data indicates that high proficiency students reported have higher mean score in two factors of CQ compares to the low proficiency students. To be more precise, the proficient students seemed to be influenced by metacognitive and cognitive factors while the less proficient students were directed by motivational and behavioral factors. This could be implied that less proficient students provide themselves with cultural motivation and behavior as variables which contribute to their EFL learning while the proficient students rely on the contribution of cultural metacognition and cognition variables. Another finding that could be noted is that high proficiency students reported to have relatively higher mean score in all of the six strategy categories than the low proficiency students. The proficient students used all types of strategies more frequently than the less proficient students except on the affective strategy. This result confirms the previous studies which argue that good language learners of high proficient learners tend to adopt more learning strategies and use them more frequent during the process of learning compared to low proficient learners (Abraham \& Vann, 1987; O’Malley \& Chamot, 1990).

\section{CONCLUSION}

This study has examined four main issues related to three different variables, namely; cultural intelligence, language learning strategies and English language proficiency. The first issue focused on the level of Cultural Intelligence of the students. The level of students' Cultural Intelligence was Medium. The most dominant factor which influences students' level of cultural intelligence was the Metacognitive factor while the least was Cognitive factor. Both male and female students' cultural intelligence level is influenced by metacognitive factor. The second main point is highlighting the current condition of language learning strategies used by the students. The students' language learning strategy use was in medium level. As for strategy categories, metacognitive strategy was the most frequently used strategy and affective strategy is the least frequently used. With regards to gender, both female and male students used metacognitive strategy as the most frequently used strategy and affective strategy as the least frequently used. The third issue is English proficiency level of the students. The students' proficiency level was low intermediate $(420-480)$ with almost half of the total sample is categorized in this category.

In relation to the linkage between cultural intelligence, language learning strategies and English language proficiency, the statistical analysis showed a meaningful relationship between cultural intelligence and language learning strategies. 
However, it was found that Cultural Intelligence, Language Learning Strategies, and English Language Proficiency had an insignificant correlation.

Knowing that there is a correlation between cultural intelligence and language learning strategies, therefore it is necessary for English teachers to provide a classroom where students' cultural intelligent could potentially be built as a way to improve their language learning process. Interactive tasks and cultural discussions activities could be arranged as optional classroom activities as these activities encourage students to involve in multicultural interactions which may lead to high level of cultural intelligence.

The result of this study showed that there was no correlation among cultural intelligence, language learning strategies and English language proficiency which means that this study could not confirm the proposed linkage model of the three variables. Future research is however suggested to employ different approach in revealing this relationship, i.e. using a mixed method as the design of the study or replicate the present study with university students in different geographical areas.

\section{REFERENCES}

[1] Ang, S., Van Dyne, L. \& Koh, C. (2006). Personality Correlates of the Four Factor Model of Cultural Intelligence. Group and Organization Management, 31 (1), 100-123.

[2] Bruen, J. (2001). Strategies for success: Profiling the effective learner of German. Foreign Language Annals, 34(3), $216-225$.

[3] Brumfit, C. (1984). The Practice of Communicative Teaching. Oxford: Pergamon Press.

[4] Corbett, J. (2003). An intercultural approach to English language teaching. Clevedon: Multilingual Matters

[5] Chen, G.M., and Stratosa, W.J. (2006). Intercultural awareness. In L. Samovar and R. Porter (Eds.), Intercultural Communication A reader (1 $1^{\text {th }}$ ed.) (pp.357-366). Belmont, CA: Wadsworth.

[6] Derin, A., Zeynep, C., Pinar, E., Ozlem, K., and Gökçe, K. (2009). Turkish EFL teachers' opinions on intercultural approach in foreign language education. Procedia- Social and Behavioral Sciences, 1, 1611-1616.

[7] Earley, P.C. and Ang, S. (2003). Cultural Intelligence: Individual Interactions Across Cultures. Palo Alto: CA: Stanford University Press.

[8] Gall, M.D., Gall, J. P., \& Borg. (2007). Educational Research: An Introduction ( $8^{\text {th }}$ Edition). Boston: Pearson, Inc.

[9] Gardner,R.C. and MacIntyre, P. D. (1993). A Student's Contributions to Second-language Learning. Part II: Affective variables, Language Teaching, 26:1-11.

[10] Green, John M. \& Rebecca Oxford (1995) “A Closer Look at Learning Strategies, L2 Proficiency and Sex”, TESOL Quarterly, Vol.29, No.2, 261-297.

[11] Griffith, C. \& Parr, J.M. (2000). Language Learning Strategies, Nationality, Independence and Proficiency. Independence, 28, p.7-10.

[12] Harley, B., Allen, P., Cummins, J., and Swain, M. (editors) (1990). The development of second language proficiency. Cambridge: Cambridge University Press.

[13] Khodadady, E. \& Ghahari, S. (2012). Exploring the Relationship Between Foreign Language Proficiency and Cultural Intelligence, EN, International Journal of Language Learning and Applied Linguistics World, Volume ( 1 ), 2012-12, Pages 22-30.

[14] Lado, R. (1961). Language Testing: The Construction and Use of Foreign Language Tests. London: Longman.

[15] Lange, D.L. (1990). Assessing Language Proficiency for Credit in Higher Education. ERIC Clearinghouse on Languages and Linguistics Washington DC. www.eric.ed.gov (Retrieved on 8 November 2017).

[16] Larsen-Freeman, D., \& Long, M. (1991). An introduction to second language acquisition research. London: Longman.

[17] Livermore, David. (2011). The Cultural Intelligence Difference Special Ebook Edition: Master the One Skill You Can't Do Without in Today's Global Economy. New York: AMACOM.

[18] Lustig, M. W. and Koester, J. (2010). Intercultural Competence: Interpersonal Communication across Culture. Boston: Pearson Education, Inc.

[19] Macaro, E. (2001). Learner strategies in second and foreign language classrooms. London, England: Continuum.

[20] Markum, J. (2017). Language Proficiency and Cultural Intelligence in Distance English-Language Learning. All Graduate Theses and Dissertations.669. http://digitalcommons.usu.edu/etd/6691 (Retrieved on 8 November 2017).

[21] Ng, K.Y., Van Dyne, L., and Ang, S. (2012). Cultural Intelligence: A Review, Reflections, and Recommendations for Future Research. In A.M. Ryan, F.T.L. Leong and F.L. Oswald (Eds.), Conducting Multinational Research: Applying Organizational Psychology in the workplace (pp.29-58). Washington DC, American Psychological Association.

[22] Ohio Department of Education. (2017). Proficiency and Research-Based Proficiency Targets. education.ohio.gov/Topics/Learning-in-Ohio/Foreign-Language/World-Languages-Model-Curriculum/World-LanguagesModel-Curriculum-Framework?Introduction-to-Learning-Standards/Proficiency-and-Research-Based-Proficiency-Targets (Retrieved on 8 November 2017).

[23] O’Malley, J. Michael, Anna Uhl Chamot, Gloria Stewner-Manzanares, Lisa Kupper \& Rocco P. Russo. (1985) "Learning strategies used by beginning and intermediate ESL students", Language Learning, Vol.35, No.1, 21-46.

[24] Oxford, R.L. (1990). Language Learning Strategies: What every teacher should know. Boston: Heinle and Heinle.

[25] Ramis, M., \& Krastina, L. (2010). Cultural intelligence in the school. Revista de Psicodidáctica, 15(2), 239-252.

[26] Richards, Jack, John Platt, and Heidi Weber. 1985. Longman dictionary of applied linguistics. Harlow, Essex, England: Longman.

[27] Rubin, J. (1975) “What the 'good language learner' can teach us”, TESOL Quarterly, 9 (1), 41-51.

[28] Scarino, A. (2009). Assessing intercultural competence in language learning: Some issues and considerations. Language Teaching, 42. 67-80. 
[29] Schulz, R.A. (2007). The challenge of assessing cultural understanding in the context of foreign language instruction. Foreign Language Annals, 40, 9-26.

[30] Thanasoulas, D. (2001). The importance of teaching culture in EFL classroom. Radical Pedagogy. https://media.startalk.umd.edu/workshops/2009/SeattlePS/sites/default/files/files/The\%20Importance\%20Of\%20Teaching\%20 Culture\%20In\%20The\%20Foreign\%20Language\%20Classroom.pdf (Retrieved on 8 November 2017).

[31] Van Dyne, L., Ang, S., \& Koh, C.K.S. (2009). Cultural Intelligence: Measurement and Scale Development. In M.A. Moodian (Ed.), Contemporary Leadership and Intercultural Competence: Exploring the cross-cultural dynamics within organization (pp. 233-254). Thousands Oaks: Sage.

[32] Wharton, G. (2000). Language Learning Strategy Use of Bilingual Foreign Language Learners in Singapore. Vol. 50 (2). Pp. 203-243.

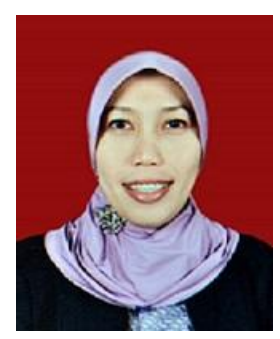

Noor Rachmawaty is a lecturer at English Department, Faculty of Education, Mulawarman University. Her Master's degree in TESOL-International was obtained from Monash University - Australia and is currently a doctorate candidate at State University of Makassar majoring English Education. Her research interests cover English language teaching and Culture.

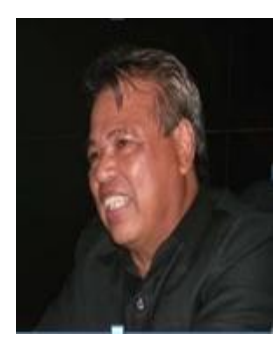

M. Basri Wello is a Professor at State University of Makassar. He earned his Master degree at Kansas University, United States of America and completed his Doctoral Degree at Hasanuddin University in 1999, Makassar Indonesia. He is also the Rector At Universitas Indonesia Timur, Makassar. His strong background is in ESP, Cross Cultural Communication and Business English.

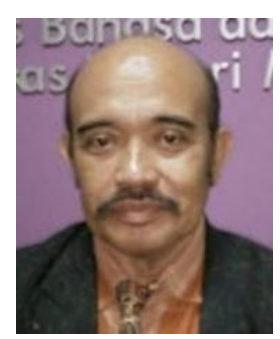

Mansur Akil is a Professor at State University of Makassar. He obtained his Doctoral degree at Universitas Hasanuddin in 2007. He is Senior lecturer on: Language Philosophy, Theory Construction and Model Building, Translation, Systems Theory, and Research Methodology.

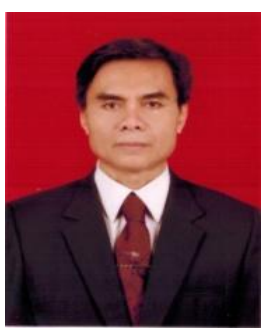

Syarifuddin Dollah got his master's degree in English Language Education from the State University of Malang and a doctorate degree in English Language Studies in 2006 at the State University of Makassar. Currently he is the Dean for Languages and Literature Faculty, State University of Makassar, Indonesia. His research works cover Cross Cultural Communication, Learning Strategies. He has written a book entitled Self esteem, Anxiety and Gender in Oral Communication of EFL Students. Pustaka Ramadhan, Bandung, Indonesia, 2016. 